KLEIST-JAHRBUCH 2002 


\title{
KLEIST-JAHRBUCH 2002
}

\author{
Im Auftrag des Vorstandes \\ der Heinrich-von-Kleist-Gesellschaft \\ herausgegeben von \\ Günter Blamberger \\ (verantwortlich für Abhandlungen), \\ Sabine Doering und Klaus Müller-Salget \\ (verantwortlich für Rezensionen)
}

VERLAG J. B. METZLER

STUTTGART · WEIMAR 


\author{
Anschrift der Redaktion: \\ Ingo Breuer (verantwortlicher Redakteur), \\ Pamela Moucha und Dominik Paß \\ Universität zu Köln, Institut für Deutsche Sprache und Literatur, \\ Albertus-Magnus-Platz, D-50931 Köln \\ eMail: ingo.breuer@uni-koeln.de
}

Die Deutsche Bibliothek - CIP-Einheitsaufnabme

Kleist-Jahrbuch ... / - Stuttgart : Metzler.

Erscheint jährlich. - Früher im Verl. E. Schmidt, Berlin. -

Aufnahme nach 1990 (1991)

ISSN 0722-8899

1990 (1991) -

Verl.-Wechsel

ISBN 978-3-476-01930-1

ISBN 978-3-476-02896-9 (eBook)

DOI 10.1007/978-3-476-02896-9

Dieses Werk einschließlich aller seiner Teile ist urheberrechtlich geschützt.

Jede Verwertung außerhalb der engen Grenzen des Urheberrechtsgesetzes ist ohne Zustimmung des Verlages unzulässig und strafbar. Das gilt insbesondere für Vervielfältigungen, Übersetzungen, Mikroverfilmungen und die Einspeicherung und Verarbeitung in elektronischen Systemen.

(C) 2002 Springer-Verlag GmbH Deutschland

Ursprünglich erschienen bei Verlag J.B. Metzlersche Verlagsbuchhandlung und Carl Ernst Poeschel Verlag GmbH in Stuttgart 2002

www.metzlerverlag.de

info@metzlerverlag.de 


\section{INHALT}

\section{Verleibung des Kleist-Preises 2001}

Adrienne Goehler: Grußwort zur Verleihung des Kleist-Preises an Judith Hermann im Deutschen Theater am 24. 11. 2001 . . . . . . . . . . . . . . .

Günter Blamberger: Rede zur Verleihung des Kleist-Preises an Judith Hermann im Deutschen Theater in Berlin am 24. November 2001.... .

Michael Naumann: Rede zur Verleihung des Kleist-Preises 2001 an Judith Hermann

Judith Hermann: Das Paradox des Genießers. Rede zur Verleihung des Kleist-Preises

\section{Abhandlungen}

Helmut J. Schneider: Geburt und Adoption bei Lessing und Kleist .......

Monika Schmitz-Emans: Das Verschwinden der Bilder als geschichtsphilosophisches Gleichnis. >Der zerbrochne Krug im Licht der Beziehungen

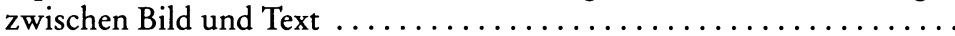

Dorothea von Mücke: >Prinz Friedrich von Homburg. Ein Schauspiek oder

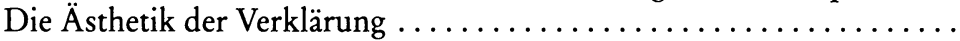

Ulrich Port: »In unbegriffner Leidenschaft empört«? Zur Diskursivierung

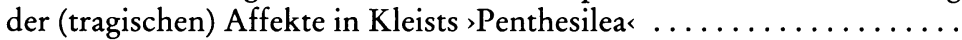

Christopher J. Wild: Wider die Marionettentheaterfeindlichkeit. Kleists Kritik bürgerlicher Antitheatralität $\ldots \ldots \ldots \ldots \ldots \ldots \ldots \ldots \ldots$

Kai Hammermeister: Kunstfeindschaft bei Kleist. Der ästhetische Diskurs in

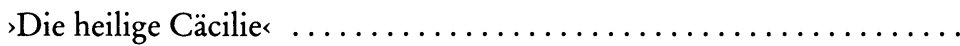

Andreas Gailus: Über die plötzliche Verwandlung der Geschichte durchs Sprechen: Kleist und das Ereignis der Rede ................

Louis Gerrekens: Heinrich von Kleists literarisches Nachwirken: Storms Novelle >Im Brauer-Hause als Adaption des Trauerspiels >Die Familie Schroffenstein 


\section{Rezensionen}

Anthony Stephens: Kleist ohne Grenzen (über: László F. Földényi, Heinrich

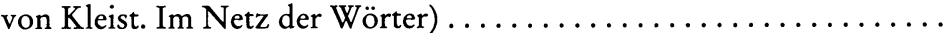

Helga Brandes: Kleist als Autor der Aufklärung? (über: Heinrich von Kleist und die Aufklärung, hg. von Tim Mehigan)

Bernd Hamacher: Altes Spannungsfeld, neu vermessen (über: Gewagte Experimente und kühne Konstellationen. Kleists Werk zwischen Klassizismus und Romantik, hg. von Christine Lubkoll und Günter Oesterle)

Siglenverzeichnis

Anschriften der Mitarbeiterinnen und Mitarbeiter .............. 212

Informationen zur Heinrich-von-Kleist-Gesellschaft . . . . . . . . . . 214 